\title{
IJTAR
}

$4(1), 118-118$

https://doi.org/10.29044/v4i1p118

International Joumal of Transactional Analysis Research

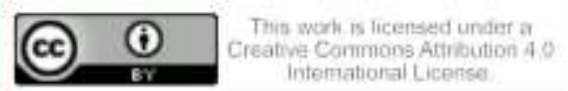

\section{Case Study Research: A Primer}

\section{(c) Mark Widdowson}

The focus of this workshop will be on the practicalities of doing case study research on your own clinical practice, covering;

- philosophy and methodology,

- issues of quality and good practice,

- case study research design

- data analysis.

The workshop will be suitable for those interested in learning how case study research can be used to investigate the process and/or outcome of TA in practice.

The workshop will be a combination of didactic presentation and group discussion.

We will refer to my articles in IJTAR, particularly: Case Study Research Methodology IJTAR 2(1) 25-34
TA Treatment of Depression - A Hermeneutic SingleCase Efficacy Design - Peter IJTAR 3(1) 3-13 plus appendices of working documents/templates

Both of these articles have been included in the delegate pack for the conference and are freely available to access at www.ijtar.org

Possible outcomes of the workshop experiences and discussions will be to:

- Stimulate practitioners to do research

- Help practitioners understand the practical use of research

- Provide a basic understanding of the principles of case study research design

- Provide an understanding of the principles of case study data analysis 